\title{
Compressive Response of Circular Cell Polycarbonate Honeycombs Under Inplane Biaxial Static and Dynamic Loads
}

\author{
Jaeung Chung* and Anthony M. Waas ${ }^{\dagger}$ \\ Composite Structures Laboratory, \\ Department of Aerospace Engineering, \\ University of Michigan, Ann Arbor, MI, 48109-2140
}

\begin{abstract}
:
The crushing response of a polycarbonate circular cell honeycomb to inplane biaxial loading is analyzed. The study involves a combination of static and dynamic experiments. Static experiments corresponding to several different biaxial loading conditions under displacement control are carried out in two different inplane directions respectively. Dynamic experiments related to various impact forces under inplane biaxial loading in two different mutually orthogonal directions, respectively, are conducted. In the first phase of the response, the material deforms in a uniform fashion. Next, a nonlinear phase caused by the progressive localization of deformation is observed. This phase is characterized by the variation of overall (macroscopic) stiffness. The progressive localization causes the walls of each cell within the localized region to contact each other. These periodic honeycomb materials show different collapsed modes under different biaxial loading histories. Experimental measurements indicate how the magnitude of the collapse load varies and how the stress-strain response changes as a function of load biaxiality. The experimental crushing responses between static and dynamic cases are compared.
\end{abstract}

\section{Introduction}

Cellular materials such as bone, different types of wood and cork are frequently found in nature. In industry, man-made cellular materials are increasingly used to make light and stiff structures or structures

\footnotetext{
${ }^{*}$ Research Fellow.

†Professor of Aerospace Engineering, Associate Fellow AIAA.

${ }^{0}$ Copyright (C) 2002 by Anthony M. Waas. Published by the American Institute of Aeronautics and Astronautics, Inc. by permission.
}

that need to absorb energy during their service lifetime. With the increasing use of light weight materials and structures in the automotive and aerospace industry, this aspect is being studied in these arenas to ensure occupant safety while simultaneously improving structural concepts. Studying the honeycomb material by itself, subject to inplane compressive loading provides fundamental insight to understanding the mechanisms of three dimensional cellular structures.

Gibson and Ashby [1] presented expressions for the mechanical properties such as the moduli and collapse strengths of three dimensional cellular solids. Papka and Kyriakides investigated the mechanical response of circular celled honeycomb under uniaxial loading in one direction [2] and extended their work to studying the response to static biaxial loading using a specially designed loading fixture $[3,4]$. Lagace and Vizzini [5] investigated the properties of an aluminum honeycomb core in conjunction with their study to develop a sandwich column specimen for characterizing the uniaxial compressive strength of composite laminates. These authors studied several different materials and cell sizes in their experimental program. In Chung and Waas [6], it is theoretically shown that the plane normal to the cell generators for the case of perfectly circular honeycomb cells (having point contact between neighboring cells and having constant uniform cell wall thickness) is a plane of isotropy . In a real honeycomb structure, however, the wall thickness at the junction where two cells meet is neither at a point contact nor is the wall thickness equal to the nominal wall thickness elsewhere. More importantly, initially circular cells tend to become elliptic due to handling and other unintended insults. On account of these deviations from intended perfection, the honeycomb structure is best characterized as be- 
ing orthotropic rather than transversely isotropic as discussed in Chung and Waas [7].

In this paper, the collapse mechanisms of polycarbonate circular cell honeycomb under different biaxial loading conditions are investigated experimentally under static and dynamic loading. In the static experiments, honeycomb specimens were subjected to eight compressive biaxial loading histories under displacement control. In the dynamic experiments, twenty four types of experiments were conducted on the honeycomb specimens under biaxial compressive loading conditions. The Young's modulus of the polycarbonate material is $2.4 \mathrm{GPa}$, and the Poisson's ratio is 0.3 . The stress-strain curve for the polycarbonate material is shown in Figure 1. Several tests of similar specimens were carried out for repeatability and what is reported here is typical of what was found experimentally.

\section{Test Specimen Geometry}

The test specimens consist of "twelve by twelve" cells cut from a $30.5 \mathrm{~cm}$ by $30.5 \mathrm{~cm}$ sheet of honeycomb. Using an optical microscope, various quantities pertaining to the cells in the honeycomb specimens such as cell wall thickness and "radius" of cell were measured accurately. The shape of each cell in the test specimen is not perfectly circular, but deviates slightly from circularity. The distribution of aspect ratio (the ratio between the diameter in the $\mathrm{X}$-direction and the diameter in the $\mathrm{Y}$-direction for each cell of the specimen) is shown in Figure 2. Also, Figure 2 shows the mean values of "a" (the diameter in the X-direction), "b" (the diameter in the Y-direction) and " $t$ " (single wall thickness) obtained using an optical microscope. As shown in Figure 3, the wall thickness of a single cell varies along the cell circumference. The values of a single wall thickness and double wall thickness (corresponding to the region of contact between neighboring cells) are as shown in Figure 3.

\section{Static Case}

\subsection{Experimental Procedure}

Static compressive experiments were conducted under displacement control in a hydraulically actuated biaxial load frame (Figure 4). A typical biaxial test is conducted as follows: First, the honeycomb specimen is loaded in the $\mathrm{X}(\mathrm{Y})$ direction uniaxially to a pre-determined load level. During this loading, the $\mathrm{Y}(\mathrm{X})$ loading plates remain flush with the honey- comb specimen, constraining any lateral expansion. Next, the $\mathrm{Y}(\mathrm{X})$ direction loading commences, with the $\mathrm{X}(\mathrm{Y})$ actuator held fixed. The loading conditions for such a series of tests are as shown in Table 1. The stress ${ }^{1}$ and strain $^{2}$ responses corresponding to these tests are schematically shown in Figure 5 where the illustration corresponds to a test in which the initial loading is in the $\mathrm{X}(\mathrm{Y})$ direction, followed by straining in the $\mathrm{Y}(\mathrm{X})$ direction. Notice that at time $\mathrm{t}=0$, when the test commences, both stress components increase, while only one strain component increases until time $\mathrm{t}=\mathrm{T}$. At $\mathrm{t}=\mathrm{T}$, the initial loading is held fixed, while the other loading is continued until the specimen collapses. Load cell data and cross head movement as a function of time are recorded. Furthermore, a high resolution video camera placed in front of the test specimen records the cell deformation throughout. The loading history and a $35 \mathrm{~mm}$ SLR camera are used to obtain selective photos during the tests. All tests are conducted in a quasi-static fashion with a cross-head speed of $0.025 \mathrm{~mm} / \mathrm{sec}$.

\subsection{Static Compressive Loading in the $\mathrm{X}$-direction under $\mathrm{Y}$ - direction Constraint}

The experimental response of a honeycomb specimen under a static compressive loading in the $\mathrm{X}$ direction with an initial stress of 0 in the Y-direction is as shown in Figure 6. This figure shows two responses which are the stress-strain response in the $\mathrm{X}$ direction (Figure 6(a)) and the stress-time response in the Y-direction (Figure 6(b)). A temporal scale related to the strain in the $\mathrm{X}$-direction is shown in Figure 6(a). Figure 6(c) shows a sequence of deformed configurations of the specimen in the experiment.

In the first phase of the experimental response, the specimen deforms in a symmetric mode (see Fig. 7(c):exs-b01). The slopes of the stressstrain response in the $\mathrm{X}$-direction and the stresstime response in the $\mathrm{Y}$-direction begin to change at the same time. In this phase, the specimen is stable because the stress increment required for further deformation of the specimen is positive. As seen in Figure 6(c):exs-b02, deformation localization in the cells develops in a scattered manner with "pockets" of localization. Further deformation of the localized

\footnotetext{
${ }^{1}$ This is the load cell reading divided by the initial undeformed cross sectional area that bears the load. We refer to this merely as stress.

${ }^{2}$ This is the displacement normalized by the undeformed height of the specimen. We refer to this merely as strain.
} 
cells results in the slopes of the responses undergoing continuous change. The development of localization is clearly seen, starting with Figure 6(c):exs-b04 and proceeding upto Figure 6(c):exs-b06. A fully developed pattern of localization is as indicated in Figure 8(a). The stress in the Y-direction reaches a maximum $(24 \mathrm{KPa})$ while, the corresponding stress in the $\mathrm{X}$-direction is $53 \mathrm{KPa}$, which is still below the maximum stress that was observed in that direction. When the stress in the $\mathrm{X}$-direction reaches a maximum $(55 \mathrm{KPa})$, the $\mathrm{Y}$-direction stress reduces to $23 \mathrm{KPa}$ which occurs beyond the maximum stress in that direction (with respect to time). Figure 6(c):exs-b05 corresponds approximately to the time at which the $\mathrm{X}$-direction stress reaches a maximum. In Figure 6(c):exs-b05, localized shapes as indicated in Figure 8(a) are found periodically and further deformation of the specimen makes these pockets of localization spread out as seen in Figure 6(c):exsb06, while, at the same time severe collapse of some of the cells are indicated.

\subsection{Static Compressive Loading in the $\mathrm{Y}$-direction under $\mathrm{X}$ - direction Constraint}

The experimental response of a honeycomb specimen under a static compressive stress in the Y-direction with an initial stress of $24 \mathrm{KPa}$ in the $\mathrm{X}$-direction are shown in Figure 7. There are two responses indicated, which are the stress-strain response in the Y-direction (Figure $7(\mathrm{a})$ ) and the stress-time response in the $\mathrm{X}$-direction (Figure 7(b)). A temporal scale related to the strain in the Ydirection is shown in Figure 7(a). Also, Figure 7(c) shows a sequence of deformed configurations of the specimen in the experiment.

In the first phase of the experimental response, the specimen deforms in a symmetric mode (see Figure 7(c):eys-b21). The slopes of the stressstrain response in the Y-direction and the stresstime response in the $\mathrm{X}$-direction begin to change at the same time. This implies a reduction in the stiffness of the specimen which is caused by deformation localization limited to a few cells. As seen in Figure 7(c):eys-b22, the localization progresses in a scattered manner involving other clusters of cells. Further deformation results in a gradually changing specimen stiffness. In Figure 7(c):eys-b23, a "zig-zag shaped localization pattern" (Figure 8(b)) occurs in some cells situated three rows below the top row and the localization shape as shown in Figure 8(a) is seen to develop in some cells situated six rows from the bottom row. In Figure 7(c):eys-b24, the zig-zag shaped localization pattern and the localization shape shown in Figure 8(a) propagates from the top row and from the bottom row respectively. The stress from the stress-time response in the $\mathrm{X}$ direction reaches a maximum value $(50 \mathrm{KPa})$ while, at this time, the stress in the Y-direction $(41 \mathrm{KPa})$ is not at the maximum, instead is still increasing towards a maximum. The stress in the Y-direction is seen to increase continuously until the end of this experiment as indicated in Figure 7(a). Notice the zigzag shaped localization pattern which is developed in the fifth row (from the top) and the localization pattern shown in Figure 8(a) which is developed in the fifth row from the bottom row. Other rows in the specimen show localized patterns that are a combination of the two basic patterns shown in Figure $8(\mathrm{a})$ and Figure 8(b).

\section{Dynamic Case}

\subsection{Experimental Procedure}

Dynamic compressive experiments of the honeycomb specimens were carried out under impact biaxial loading conditions in a drop test facility (Figure 9). To record the biaxial loading data through the top and side load cells, and acceleration data through an accelerometer mounted on the upper solid block, an oscilloscope is used. The oscilloscope can acquire digitized data at high sampling rates (maximum sampling rate of the oscilloscope is $2 \mathrm{GHz}$ ). In the biaxial dynamic experiments, a sampling rate of $10 \mathrm{KHz}$ is used for the oscilloscope. Displacement data of the test specimen are obtained after double integration of the acceleration data. Load cell data and acceleration data as a function of time are recorded. A high speed digital camera is used to take deformed shapes of the honeycomb specimens. The camera has a maximum framing rate of 1000 frames/sec, for a total duration of 2.8 secs. In the present experiments, this maximum framing rate is used for the high speed digital camera to capture the deformed shapes of the test specimens. Three different heights $\left(h_{1}, h_{2}, h_{3}\right.$; the initial distance between the upper loading plate and top of the test specimen) and velocities in each direction are shown in Figure 10. The initial impact velocity of the upper loading plate $\left(v_{1}, v_{2}, v_{3}\right.$; see Figure 10$)$ is obtained using the following simple equation.

$$
m g h=\frac{1}{2} m v^{2} \rightarrow v=\sqrt{2 g h} .
$$

For the heights used in the present experi- 
ment, this equation was found to be accurate upto $97 \%$ of the value measured, when calibrated against measurements made through the images of the high speed camera.

Typical stress vs. time and strain vs. time responses related to these tests are schematically shown in Figure 11. As seen in Figure 11, each figure has a time axis which is separated into two time periods, $T$ and $T^{*}$. For times, $t<T$, the test specimen has been loaded in the $\mathrm{X}(\mathrm{Y})$ direction and there is no constraint in the $\mathrm{Y}(\mathrm{X})$ direction. Furthermore, during this time period, the test specimen is held fixed in the $\mathrm{X}(\mathrm{Y})$ direction and the impact loading plate is dropped in the $\mathrm{Y}(\mathrm{X})$ direction. The stress and strain components in the $\mathrm{X}(\mathrm{Y})$ direction are held fixed, while the stress and strain components in the $\mathrm{Y}(\mathrm{X})$ direction are zero until time $t=T$. For $t>T$, the test specimen is held fixed in the $\mathrm{X}(\mathrm{Y})$ direction and the specimen starts to collapse in the $\mathrm{Y}(\mathrm{X})$ direction and continues to collapse in the $\mathrm{Y}(\mathrm{X})$ direction until the end of the experiment. During this time period indicated by $T^{*}$, the stress components in the $\mathrm{X}(\mathrm{Y})$ direction and the stress and strain components in the $\mathrm{Y}(\mathrm{X})$ direction start to increase while the strain components in the $\mathrm{X}(\mathrm{Y})$ direction is held constants. In the dynamic experiments, the falling mass gives rise to a time varying nominal stress history in the impactor direction, however, the side constraints provide the lateral stresses resulting in non-proportional loading at later times in the loading history.

\subsection{Dynamic Compressive Loading in the $\mathrm{X}$-direction under $\mathrm{Y}$ - direction Constraint}

The experimental response of a honeycomb specimen under an impact compressive loading corresponding to an initial impact velocity of $585 \mathrm{~mm} / \mathrm{sec}$ in the $\mathrm{X}$ direction with an initial stress of 0 in the $\mathrm{Y}$ direction is as shown in Figure 12. This figure shows two responses which are the stress-strain response in the $\mathrm{X}$ direction (Figure 12(a)) and the stress-time response in the $\mathrm{Y}$ direction (Figure 12(b)). A temporal scale related to the strain in the $\mathrm{X}$ direction is shown in Figure 12(a). Figure 12(a) shows the variation of the $\mathrm{X}$ direction stress upto the maximum strain experienced by the test specimen due to impact loading in the $\mathrm{X}$ direction and Figure 12(b) shows the variation of the stress in the $\mathrm{Y}$ direction during the same time period.

Experimental observations are explained as follows. In the first phase of the experimental response, the specimen deforms in a uniform fash- ion (Figure 12(c):exd-b01). The slope of the stressstrain response in the $\mathrm{X}$ direction begins to change at a $\mathrm{X}$ direction macroscopic stress of $45 \mathrm{KPa}$ and the corresponding $\mathrm{X}$ direction macroscopic strain of $1.7 \%$ while, the slope of the stress-time response in the $\mathrm{Y}$ direction starts to change at a $\mathrm{Y}$ direction macroscopic stress of $24 \mathrm{KPa}$. As seen in Figure 12(c):exd-b02, deformation localization develops in a scattered manner throughout the specimen. The time required for the $\mathrm{Y}$ direction stress to reach a maximum is less than that required for the $\mathrm{X}$ direction stress to reach a maximum. The development of localization is clearly seen in Figure 12(c):exdb03. A pattern of the localization is shown in Figure $8(\mathrm{a})$. In this figure, the localization in the specimen is more severely developed in the right part of the specimen when compared to the left part. Such a phenomena of deformation localization is clearly seen in Figure 12(c):exd-b04 and exd-b05 due to severe development of the localization shown in Figure $8(\mathrm{a})$.

\subsection{Dynamic Compressive Loading in the $\mathrm{Y}$-direction under $\mathrm{X}$ - direction Contsraint}

The experimental response of a honeycomb specimen subjected to an initial impact velocity of 702 $\mathrm{mm} / \mathrm{sec}$ in the $\mathrm{Y}$ direction with an initial stress of $24 \mathrm{KPa}$ in the $\mathrm{X}$ direction is as shown in Figure 13. This figure shows two responses which are the stressstrain response in the $\mathrm{Y}$ direction (Figure 13(a)) and the stress-time response in the $\mathrm{X}$ direction (Figure 13(b)). A temporal scale related to the strain in the $\mathrm{Y}$ direction is shown in Figure 13(a). Also, Figure 13(c) shows a sequence of deformed configurations of the specimen in the experiment. Figure 13(a) shows the variation of the $\mathrm{Y}$ direction stress upto the maximum strain experienced by the specimen in the $\mathrm{Y}$ direction and Figure 13(b) shows the variation of stress in the $\mathrm{X}$ direction during this time period.

As seen in Figure 13(c):eyd-b21, initiation of a localized deformation pattern such as that in Figure $8(\mathrm{a})$ is observed in some cells of the specimen, though the corresponding point on the response curve is in the linear region. The slope of the stress-strain response in the $\mathrm{Y}$ direction begins to change at a $\mathrm{Y}$ direction macroscopic stress of 38 $\mathrm{KPa}$ and the corresponding $\mathrm{Y}$ direction macroscopic strain is $1.7 \%$ while, the slope of the stress-time response in the $\mathrm{X}$ direction starts to change at a $\mathrm{X}$ direction macroscopic stress of $37 \mathrm{KPa}$. Development of the localization is clearly seen in Figure 13(c):eyd-b22. The stress in the Y direction reaches 
a maximum $(50 \mathrm{KPa})$ at a strain $(5.6 \%)$ while, the corresponding stress in the $\mathrm{X}$ direction is $41 \mathrm{KPa}$ at a time $(0.0048 \mathrm{sec})$. When the stress in the $\mathrm{X}$ direction reaches a maximum $(47 \mathrm{KPa})$ at a time $(0.0024 \mathrm{sec})$, the corresponding $\mathrm{Y}$ direction stress is still $44 \mathrm{KPa}$ (less than the maximum and still ascending) at a strain (3.2\%). In Figure 13(c):eyd-b23, a "zig-zag shaped localized pattern" (Figure 8(b)) occurs in some cells situated three rows below the top row and the localization shape as shown in Figure $8(\mathrm{a})$ is fully developed in the other cells. The progressive development of the localization pattern of Figure $8(\mathrm{a})$ and the zig-zag shaped localization pattern of Figure 8(b) is clearly observed in Figure 13(c):eyd-b24, Figure 13(c):eyd-b25 and Figure 13(c):eyd-b26. In this experiment, the localization pattern indicated in Figure 8(a) is developed prior to that of the zig-zag shaped localization. Initiation of the localization pattern of Figure 8(a) begins in the linear region of the response and the zig-zag shaped localization commences after the attainment of the maximum stress in the $\mathrm{Y}$ direction.

\section{Discussion}

Hexagonally packed imperfect circular cell honeycombs are orthotropic as contrasted with transverse isotropy which is evident in hexagonally packed perfect circular cell honeycombs. This induced orthotropy in circular cell honeycombs is due to cell ellipticity and imperfect cell wall contact between neighbors (line contact as opposed to point contact). This aspect was investigated in the context of examining the uniaxial crushing response of honeycombs as discussed in Chung and Waas [7]. The linear static stiffness of the biaxial response is affected by several factors such as cell size, wall thickness variation for each cell, imperfection at the points (regions) of contact between neighboring cells and deviation from circularity for each cell of the specimen. In the biaxial experiment, the shape of deformation localization appears as a combination of the localization pattern of Figure 8(a) and the zig-zag shape shaped localization (Figure 8(b)). This phenomenon appears more clearly and severely according to the initial biaxial loading state. As the initial transverse load increases, the localization patterns are distinct and diffused. Table 2 and Table 3 show the Young's moduli of the honeycomb material under different biaxial loading conditions. As seen in Table 2 and Table 3 , the linear stiffness of the honeycomb material increases according to the amount of initial transverse stress. This is to be expected since an initial transverse compressive stress results in a compressively "stiffer" specimen. The stiffness of the honeycomb material under biaxial loading conditions is also higher than that under uniaxial loading conditions due to the above reason. The linear stiffness of the material is not affected by the magnitude of the initial impact velocity. Hence, the Young's modulus of the honeycomb material in the impact loading direction is dependent of the initial loading constraint in the transverse direction and is independent of the initial impact velocity. From the dynamic experimental results, it is seen that the maximum stresses in the impact loading direction and the maximum stress in the transverse direction do not occur at the same time. The maximum stress in the impact loading direction occurs later than the maximum stress in the transverse direction. In all the biaxial dynamic experiments, the maximum stress of the material always occurs earlier than the attainment of the maximum strain (see Figure 12(a) and Figure 13(a)). Figure 14(a) and Figure 14(b) show the maximum stress envelope including the experimental results of the uniaxial cases discussed earlier (static and dynamic case; Chung and Waas [7]) and biaxial static and dynamic cases studied here. In this figure, a circle and a square stand for the maximum stress of the static experiment and the maximum stress of the dynamic experiments with different initial impact velocities, respectively. The values in Figure 14(a) and Figure 14(b) represent the maximum stresses in the transverse direction (initial loading constrained direction) and the corresponding stresses in the loading direction. From the experimental results, the maximum stress in the transverse direction and the maximum stress in the loading direction do not coincide on a temporal scale. For comparison purpose, Figure 15(a) and Figure 15(b) are included to show the maximum stress envelope occurring in the loading direction stress-strain curve.

\section{Concluding Remarks}

Results from an experimental study on the static and dynamic inplane biaxial compressive response of circular cell polycarbonate honeycombs have been presented. Inplane failure envelopes, much like yield surfaces for homogeneous elastic-plastic solids, have been presented. The honeycomb materials, although nominally transversely isotropic, are seen to exhibit inplane orthotropy due to unintended cell level imperfections. Initially, the specimens exhibit nearly uniform behavior. At a certain level of external load, deformation localization occurs. The localiza- 
AIAA-2002-1244

tion patterns are a combination of some fundamental inplane cell buckling modes. These modes have been presented and further analyzed in a companion paper [9]. The experimental results and the failure envelopes are useful towards the development of a $3 \mathrm{D}$ orthotropic continuum description of the macroscopic response of the honeycombs.

\section{$\underline{\text { References }}$}

[1] L. J. Gibson and M. F. Ashby, "The mechanics of three-dimensional cellular materials", Proc. R. Soc.,A 382, pp. 43, 1982.

[2] S. D. Papka and S. Kyriakides, "In-plane crushing of a polycarbonate honeycomb", Int. J. Solids Structures, Vol. 35, pp. 239, 1998.

[3] S. D. Papka and S. Kyriakides, "In-plane biaxial crushing of honeycombs:Part I experiment", Int. J. Solids Struct., Vol 36 (29), pp. 4367, 1999.

[4] S. D. Papka and S. Kyriakides, "In-plane biaxial crushing of honeycombs:Part II analysis", Int. J. Solids Struct., Vol 36 (29), pp. 4397, 1999.

[5] Paul A. Lagace and Anthony J. Vizzini, "The sandwich column as a compressive characterization specimen for thin laminates", ASTM STP 972,Vol. 46, pp. 143, 1988.

[6] J. Zhang and M. F. Ashby, "The out-ofplane properties of honeycombs", Int. J. Mech. Sci.,Vol. 34, pp. 475, 1992.

[7] J. Chung and A. M. Waas, "The inplane elastic properties of circular cell and elliptic cell honeycombs", Acta Mechanica, Vol. 144, No. 1-2, pp. $29,2000$.

[8] J. Chung and A. M. Waas, "Compressive response and failure of circular cell polycarbonate honeycombs under inplane uniaxial stresses", $J$. Eng. Mat. Tech., Vol. 121, No. 4, pp. 494, 1999.

[9] J. Chung and A. M. Waas, "Compressive response of circular cell polycarbonate honeycombs under inplane biaxial static and dynamic loading-Part 2:simulations", Int. J. Impact Eng., accepted to appear, 2002.

\begin{tabular}{|l|l|l|}
\hline \hline $\begin{array}{l}\text { Test } \\
\text { number }\end{array}$ & X loading & Y loading \\
\hline 1 & active & initial stress of $0 \mathrm{KPa}$ \\
2 & active & initial stress of $4.7 \mathrm{KPa}$ \\
3 & active & initial stress of $9.6 \mathrm{KPa}$ \\
4 & active & initial stress of $23 \mathrm{KPa}$ \\
5 & initial stress of $0 \mathrm{KPa}$ & active \\
6 & initial stress of $12.3 \mathrm{KPa}$ & active \\
7 & initial stress of $24 \mathrm{KPa}$ & active \\
8 & initial stress of $39.6 \mathrm{KPa}$ & active \\
\hline \hline
\end{tabular}

Table 1: Loading conditions for the biaxial test.

\begin{tabular}{|c|l|c|}
\hline \hline \multicolumn{2}{|c|}{$\begin{array}{c}\text { impact loading } \\
\text { in X direction }\end{array}$} & $\begin{array}{c}E_{x}^{*} \\
(\mathrm{KPa})\end{array}$ \\
\hline \hline \multirow{2}{*}{$\begin{array}{c}\text { initial stress } \\
\text { of } 0 \mathrm{KPa}\end{array}$} & $v_{1}(585 \mathrm{~mm} / \mathrm{s})$ & 2596 \\
\cline { 2 - 3 } in Y direction & $v_{2}(831 \mathrm{~mm} / \mathrm{s})$ & 2687 \\
\cline { 2 - 3 } & $v_{3}(1049 \mathrm{~mm} / \mathrm{s})$ & 2624 \\
\hline initial stress & $v_{1}(585 \mathrm{~mm} / \mathrm{s})$ & 2937 \\
\cline { 2 - 3 } of $4.7 \mathrm{KPa}$ & $v_{2}(831 \mathrm{~mm} / \mathrm{s})$ & 2973 \\
\cline { 2 - 3 } in Y direction & $v_{3}(1049 \mathrm{~mm} / \mathrm{s})$ & 3037 \\
\hline initial stress & $v_{1}(585 \mathrm{~mm} / \mathrm{s})$ & 3868 \\
\cline { 2 - 3 } of $9.6 \mathrm{KPa}$ & $v_{2}(831 \mathrm{~mm} / \mathrm{s})$ & 3799 \\
\cline { 2 - 3 } in Y direction & $v_{3}(1049 \mathrm{~mm} / \mathrm{s})$ & 3806 \\
\hline initial stress & $v_{1}(585 \mathrm{~mm} / \mathrm{s})$ & 4673 \\
\cline { 2 - 3 } of $23 \mathrm{KPa}$ & $v_{2}(831 \mathrm{~mm} / \mathrm{s})$ & 4519 \\
\cline { 2 - 3 } in Y direction & $v_{3}(1049 \mathrm{~mm} / \mathrm{s})$ & 4451 \\
\hline \hline
\end{tabular}

Table 2: Comparison of dynamic Young's moduli of the honeycomb material under biaxial loading conditions with three different initial impact velocity in the $\mathrm{X}$ direction.

\begin{tabular}{|c|c|c|}
\hline \hline \multicolumn{2}{|c|}{$\begin{array}{c}\text { impact loading } \\
\text { in Y direction }\end{array}$} & $\begin{array}{c}E_{y}^{*} \\
(\mathrm{KPa})\end{array}$ \\
\hline \hline initial stress & $v_{1}(702 \mathrm{~mm} / \mathrm{s})$ & 2596 \\
\cline { 2 - 3 } of 0 KPa & $v_{2}(917 \mathrm{~mm} / \mathrm{s})$ & 2687 \\
\cline { 2 - 3 } in X direction & $v_{3}(1118 \mathrm{~mm} / \mathrm{s})$ & 2624 \\
\hline initial stress & $v_{1}(702 \mathrm{~mm} / \mathrm{s})$ & 2937 \\
\cline { 2 - 3 } of 12.3 KPa & $v_{2}(917 \mathrm{~mm} / \mathrm{s})$ & 2973 \\
\cline { 2 - 3 } in X direction & $v_{3}(1118 \mathrm{~mm} / \mathrm{s})$ & 3037 \\
\hline initial stress & $v_{1}(702 \mathrm{~mm} / \mathrm{s})$ & 3868 \\
\cline { 2 - 3 } of 24 KPa & $v_{2}(917 \mathrm{~mm} / \mathrm{s})$ & 3799 \\
\cline { 2 - 3 } in X direction & $v_{3}(1118 \mathrm{~mm} / \mathrm{s})$ & 3806 \\
\hline initial stress & $v_{1}(702 \mathrm{~mm} / \mathrm{s})$ & 4673 \\
\cline { 2 - 3 } of 39.6 KPa & $v_{2}(917 \mathrm{~mm} / \mathrm{s})$ & 4519 \\
\cline { 2 - 3 } in X direction & $v_{3}(1118 \mathrm{~mm} / \mathrm{s})$ & 4451 \\
\hline \hline
\end{tabular}

Table 3: Comparison of dynamic Young's moduli of the honeycomb material under four different biaxial loading conditions with three different initial impact velocity in the $\mathrm{Y}$ direction respectively. 

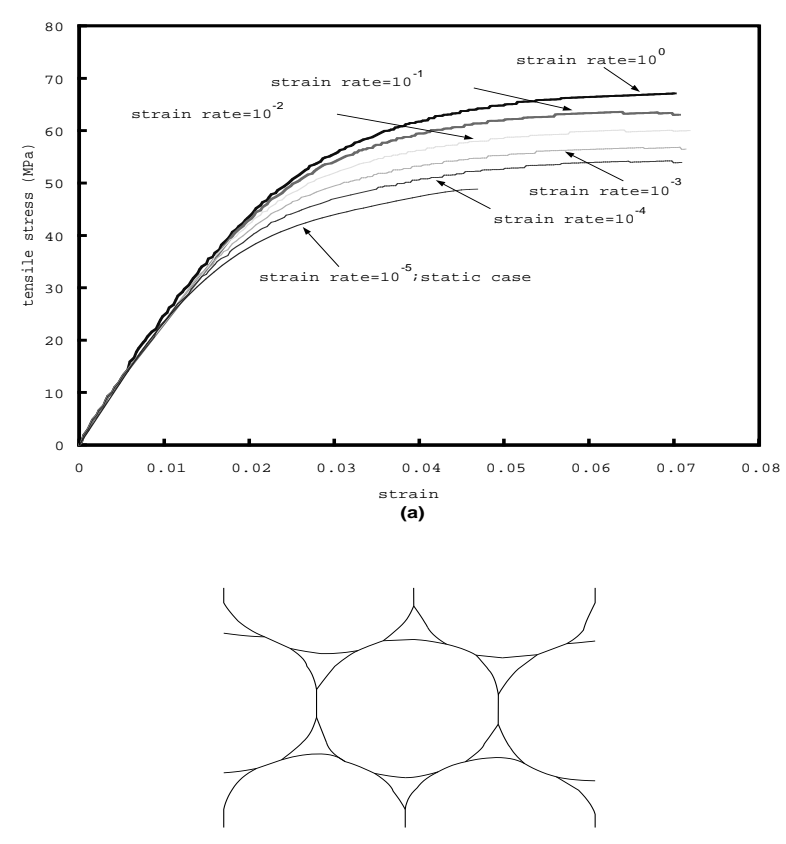

(b)

Figure 1: (a) The uniaxial tensile stress-strain curve for polycarbonate material. (b) A microsection of the honeycomb.
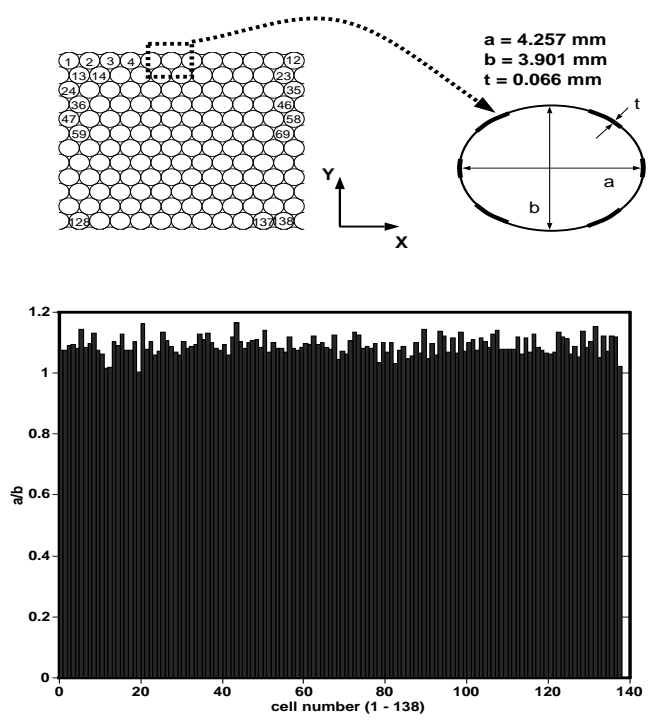

Figure 2: Cell aspect ratio distribution.
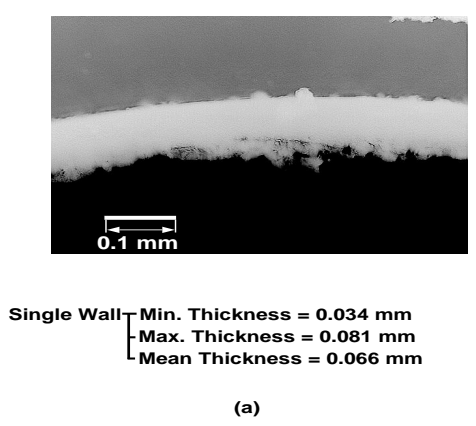

(a)

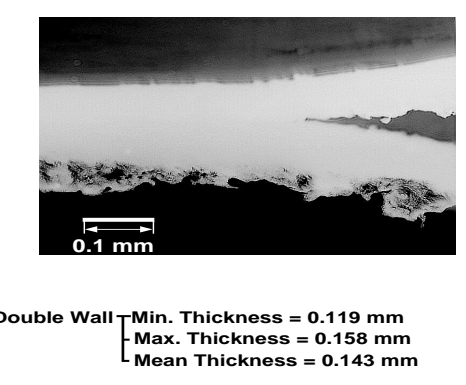

(b)

Figure 3: (a) Typical single cell wall thickness variation along each cell of honeycomb. (b) Typical double cell wall thickness variation at the junction of two neighboring cells.

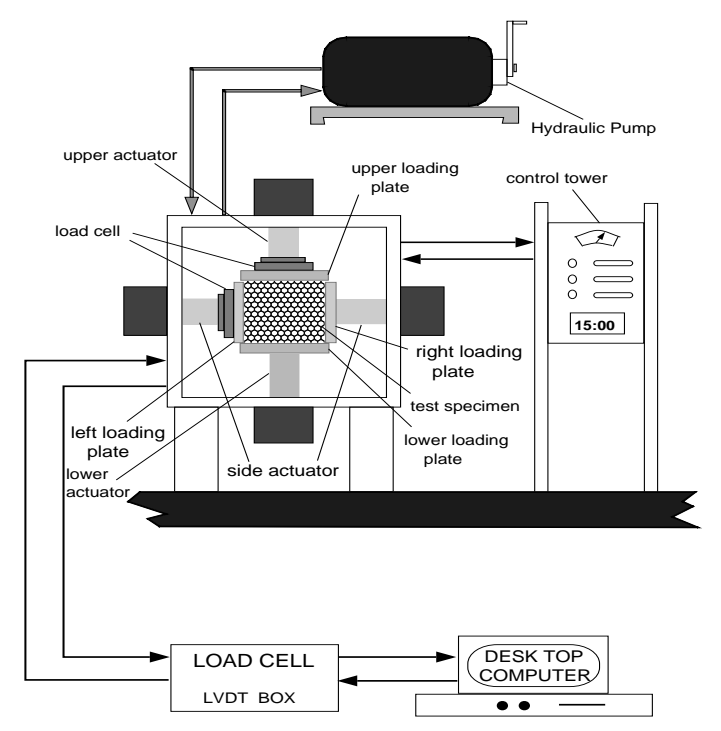

Figure 4: Schematic of test equipment used for static in-plane biaxial crushing experiment of honeycomb. 

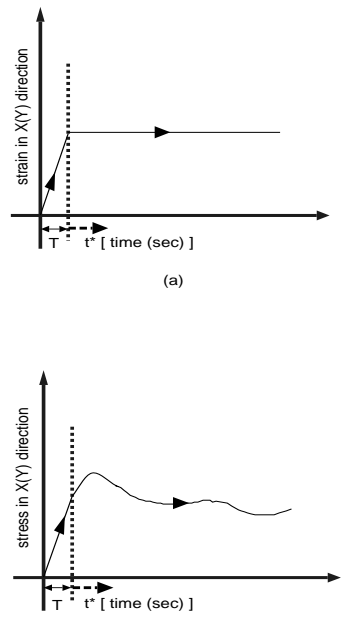

(c)

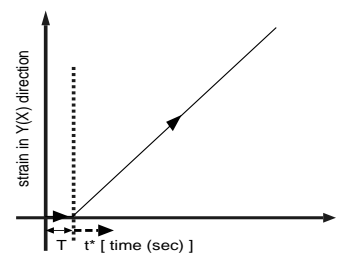

(b)

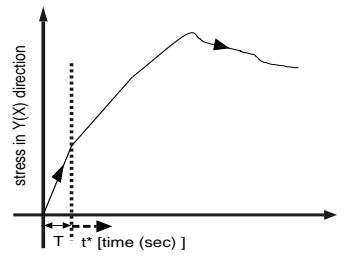

(d)
Figure 5: Schematic of static biaxial tests.

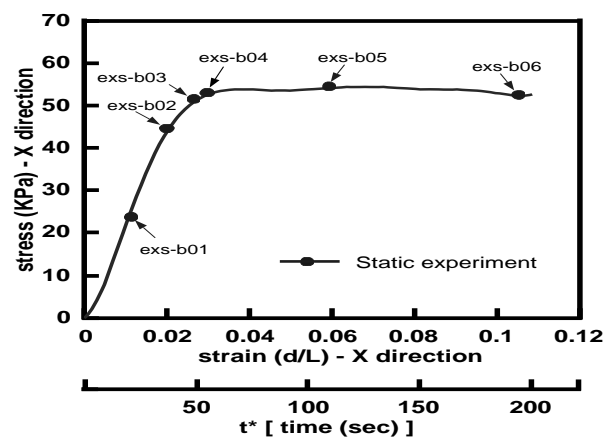

(a)

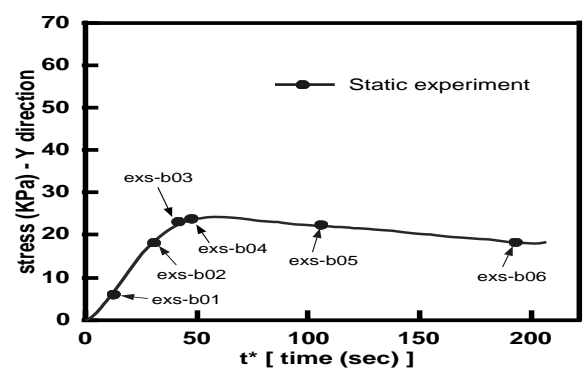

(b)

Figure 6: (a) The stress-strain response under static compressive loading in the $\mathrm{X}$-direction with initial stress of $0 \mathrm{KPa}$ in the Y-direction. (b) The corresponding stress-time response.
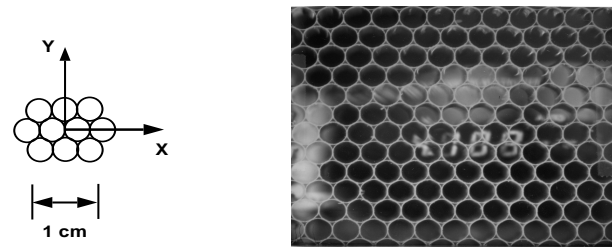

exs-b01

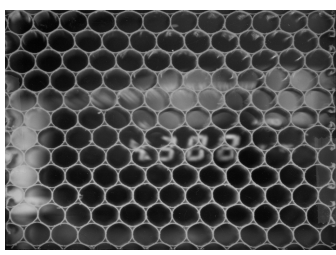

exs-b02

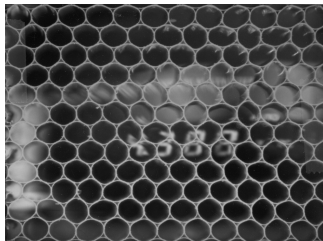

exs-b03

Figure 6: (c) Experiment -A sequence of deformed honeycomb specimen under static compressive loading in the $\mathrm{X}$-direction with initial stress of $0 \mathrm{KPa}$ in the $\mathrm{Y}$-direction.
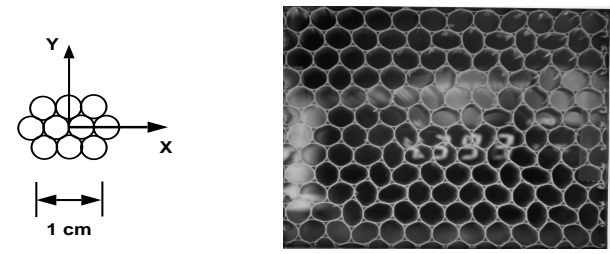

exs-b04

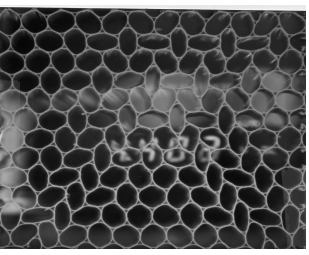

exs-b05

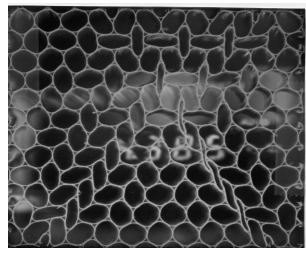

exs-b06
Figure 6: (c)-continued; Experiment -A sequence of deformed honeycomb specimen under static compressive loading in the $\mathrm{X}$-direction with initial stress of $0 \mathrm{KPa}$ in the $\mathrm{Y}$-direction. 


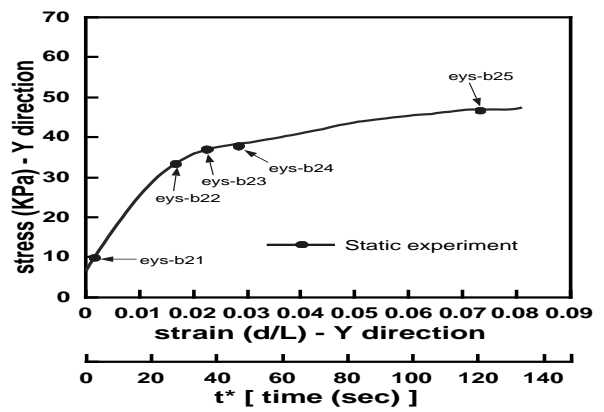

(a)

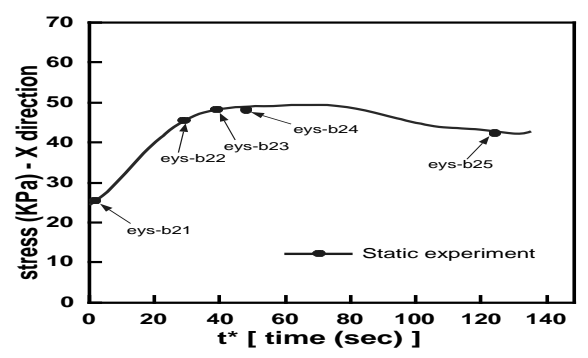

(b)

Figure 7: (a) The stress-strain response under static compressive loading in the Y-direction with initial stress of $24 \mathrm{KPa}$ in the $\mathrm{X}$-direction. (b) The corresponding stress-time response.
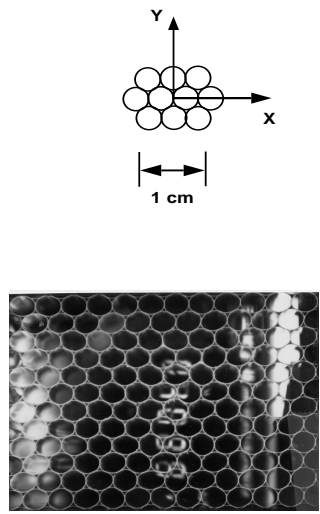

eys-b22

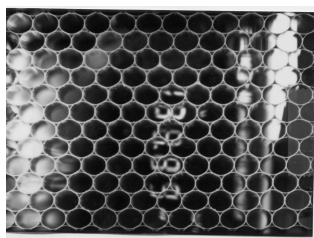

eys-b21

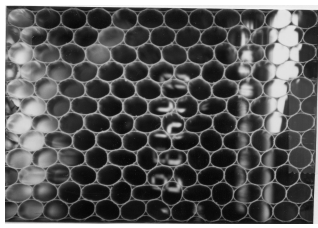

eys-b23
Figure 7: (c) Experiment -A sequence of deformed honeycomb specimen under static compressive loading in the Y-direction with initial stress of $24 \mathrm{KPa}$ in the $\mathrm{X}$-direction.

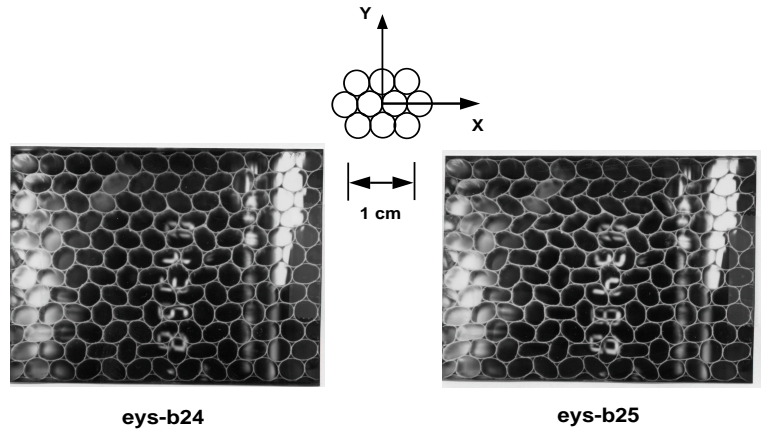

Figure 7: (c)-continued; Experiment -A sequence of deformed honeycomb specimen under static compressive loading in the Y-direction with initial stress of $24 \mathrm{KPa}$ in the $\mathrm{X}$-direction.

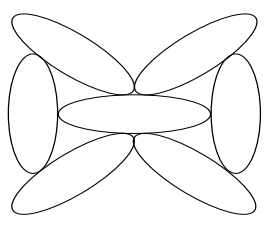

(a)

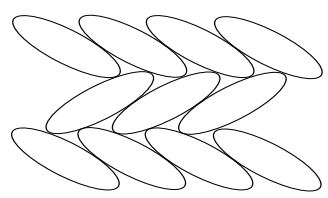

Figure 8: localized shapes shown under biaxial loading conditions.

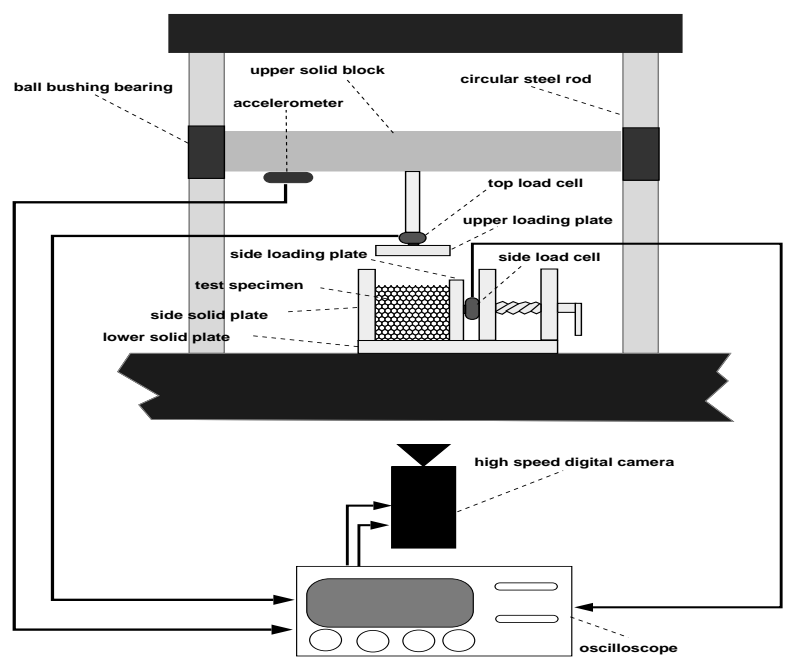

Figure 9: Schematic of test equipment used for dynamic inplane biaxial crushing experiment of honeycomb. 


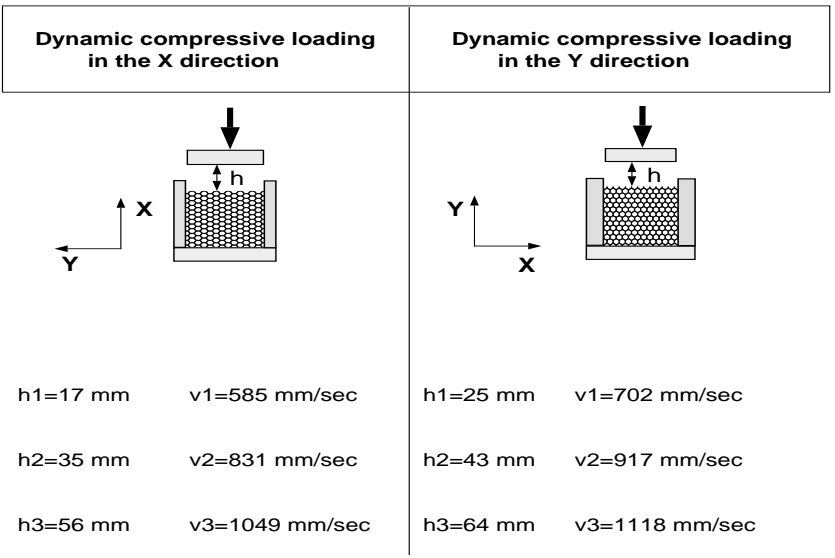

Figure 12: (a) The stress-strain response under dynamic compressive loading having an initial impact velocity of $585 \mathrm{~mm} / \mathrm{sec}$ in the X-direction with initial stress of $0 \mathrm{KPa}$ in the $\mathrm{Y}$-direction. (b) The corresponding stress-time response.

Figure 10: Three different heights and initial impact velocities of dropped upper loading plate.

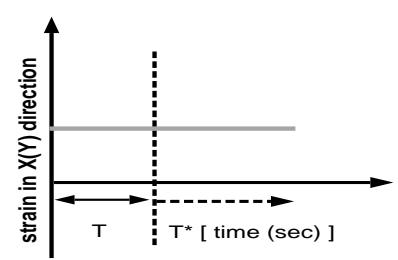

(a)

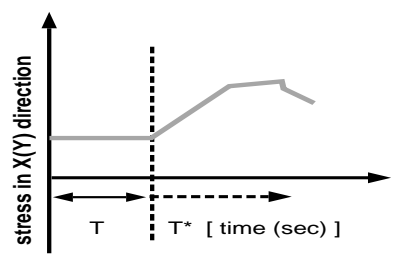

(c)

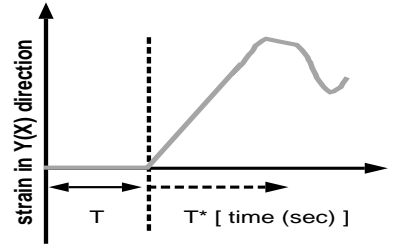

(b)

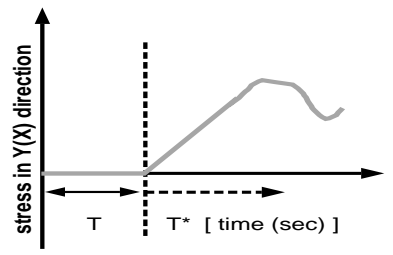

(d)
Figure 11: Schematic of dynamic biaxial tests.

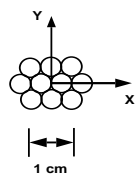

exd-b02

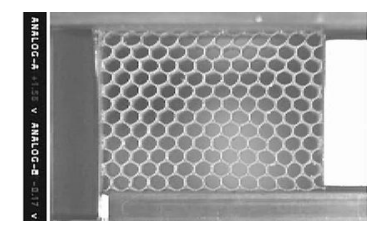

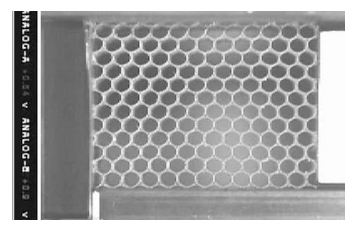

exd-b01

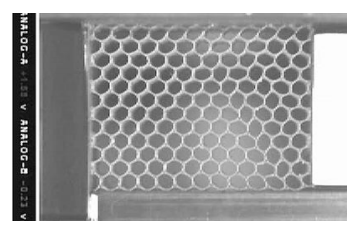

exd-b03
Figure 12: (c) Experiment -A sequence of deformed honeycomb specimen under dynamic compressive loading having an initial impact velocity of 585 $\mathrm{mm} / \mathrm{sec}$ in the $\mathrm{X}$-direction with initial stress of 0 $\mathrm{KPa}$ in the $\mathrm{Y}$-direction.
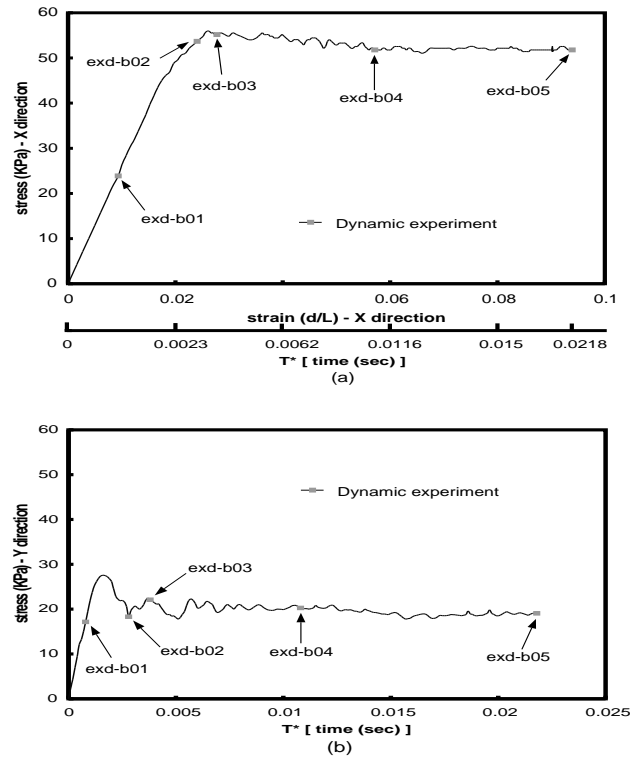

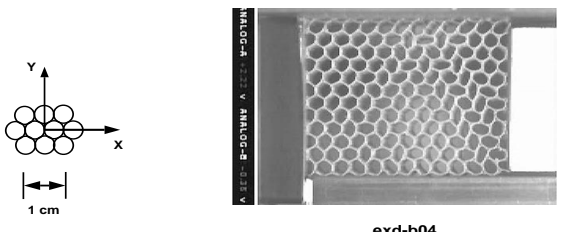

exd-b04

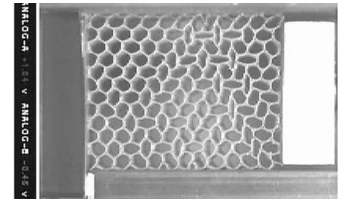

exd-b05

Figure 12: (c)-continued; Experiment -A sequence of deformed honeycomb specimen under dynamic compressive loading having an initial impact velocity of $585 \mathrm{~mm} / \mathrm{sec}$ in the X-direction with initial stress of $0 \mathrm{KPa}$ in the $\mathrm{Y}$-direction.
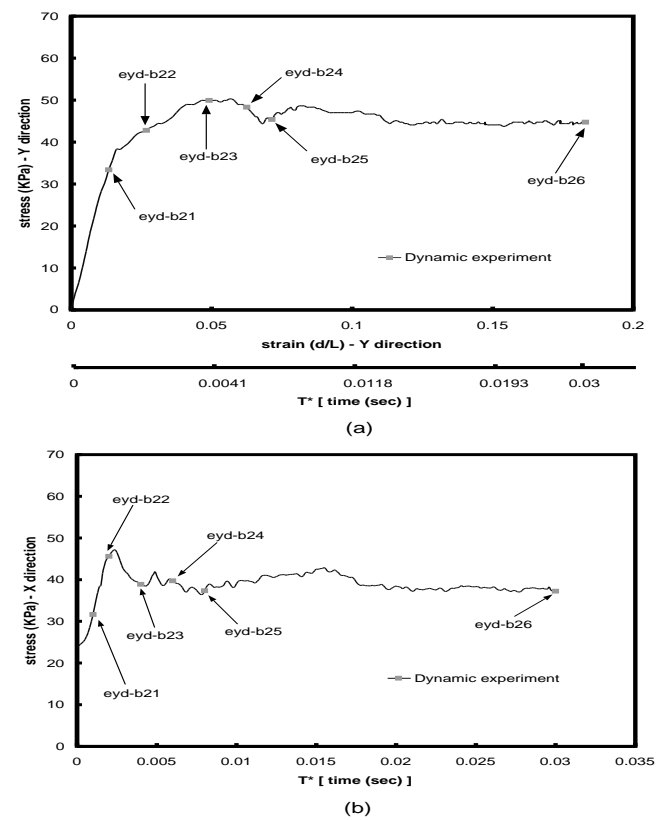

Figure 13: (a) The stress-strain response under dynamic compressive loading having an initial impact velocity of $702 \mathrm{~mm} / \mathrm{sec}$ in the Y-direction with initial stress of $24 \mathrm{KPa}$ in the X-direction. (b) The corresponding stress-time response.
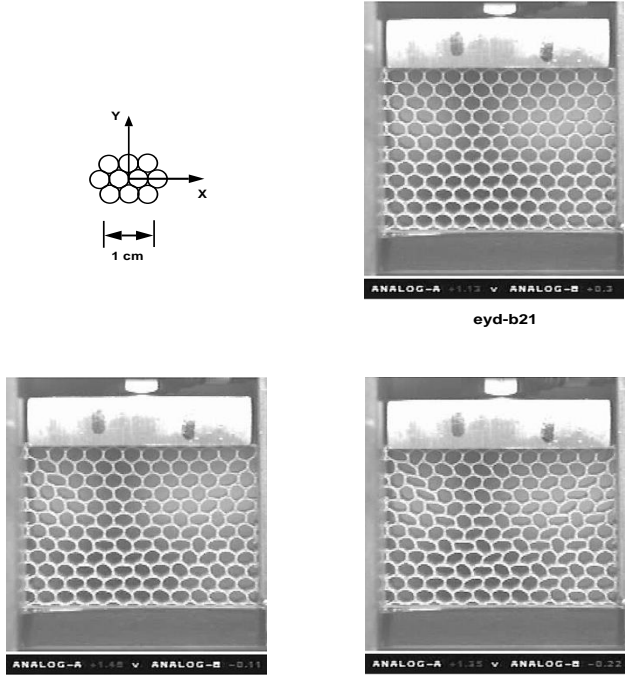

eyd-b22

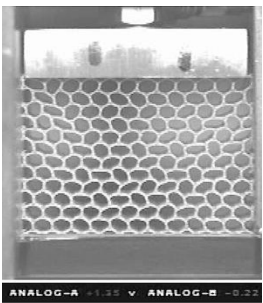

eyd-b23

Figure 13: (c) Experiment -A sequence of deformed honeycomb specimen under dynamic compressive loading having an initial impact velocity of 702 $\mathrm{mm} / \mathrm{sec}$ in the Y-direction with initial stress of 24 $\mathrm{KPa}$ in the $\mathrm{X}$-direction.
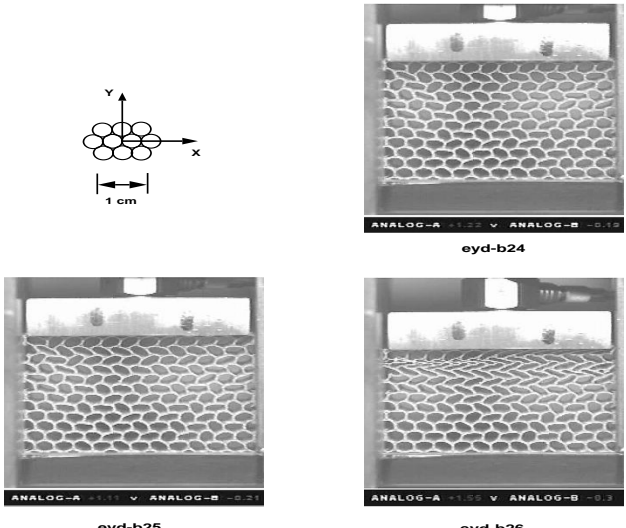

Figure 13: (c)-continued; Experiment -A sequence of deformed honeycomb specimen under dynamic compressive loading having an initial impact velocity of $702 \mathrm{~mm} / \mathrm{sec}$ in the Y-direction with initial stress of $24 \mathrm{KPa}$ in the $\mathrm{X}$-direction. 


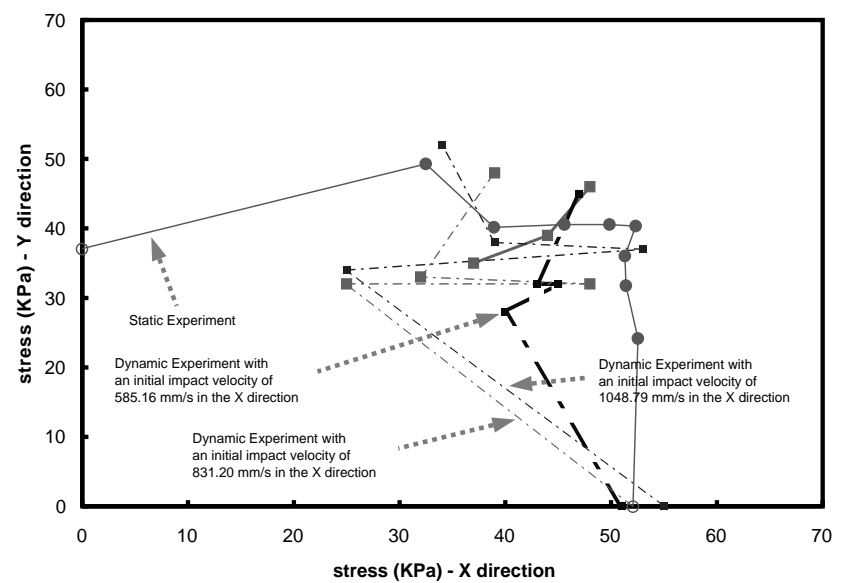

(a)

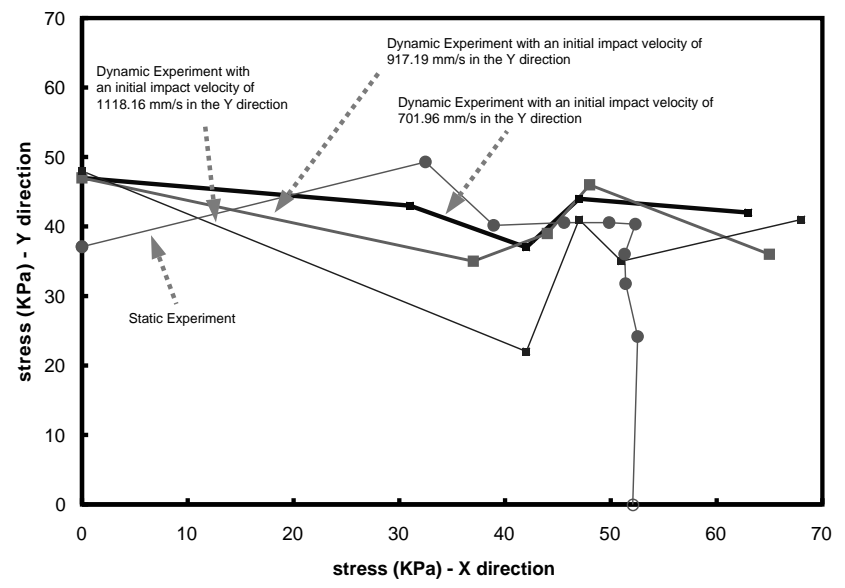

(b)

Figure 14: (a) Maximum stress envelope using the maximum stress in the stress-time response in the transverse direction and the corresponding stress in the stress-strain response in the loading direction (b) Maximum stress envelope using the maximum stress in the stress-time response in the transverse direction and the corresponding stress in the stress-strain response in the loading direction.

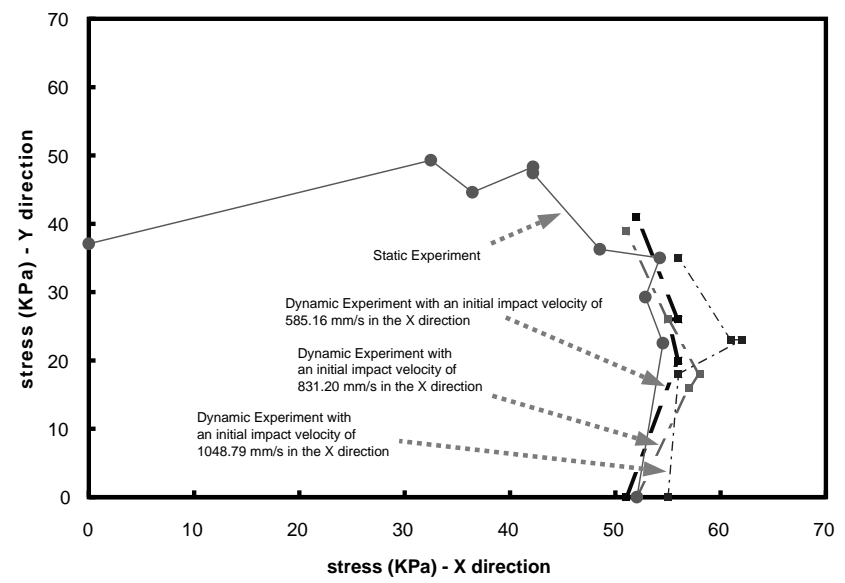

(a)

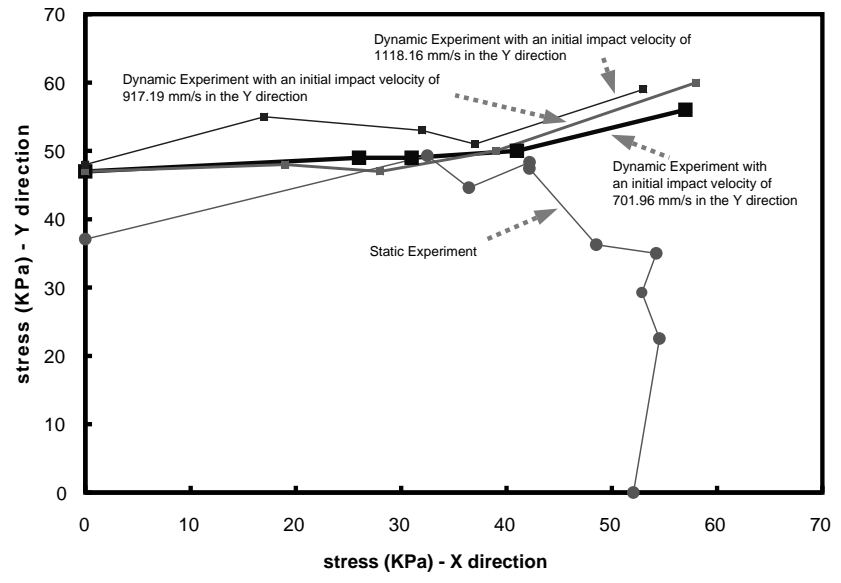

(b)

Figure 15: (a) Maximum stress envelope using the maximum stress in the stress-strain response in the loading direction and the corresponding stress in the stress-time response in the transverse direction (b) Maximum stress envelope using the maximum stress in the stress-strain response in the loading direction and the corresponding stress in the stress-time response in the transverse direction. 